\title{
Workarounds in Business Processes: A Goal-Based Analysis
}

\author{
Nesi Outmazgin ${ }^{(凶)}$, Pnina Soffer ${ }^{(凶)}$, and Irit $\operatorname{Hadar}^{(\bowtie)}$ \\ University of Haifa, Mount Carmel, 3498838 Haifa, Israel \\ nesi@zefat.ac.il, \{spnina,hadari\}@is.haifa.ac.il
}

\begin{abstract}
Workarounds in business processes and information systems (IS) have attracted research attention in recent years. Deviating from official processes, workarounds are goal-driven adaptations. Understanding the underlying problems or perceived barriers that motivate workarounds is essential for suggesting appropriate solutions which would lead to process and IS improvement. The premise taken in this paper is that workarounds are often motivated by misalignments between organizational goals, goals of local-units and actors, and the business process that should realize these goals. With this premise, we propose an $i^{*}$-based analysis for identifying such misalignments that are associated to workarounds. We report an industrial case study that demonstrates the analysis and associates workarounds with the underlying misalignments. Improvement recommendations that were made following the analysis have been accepted by the organization and are currently being implemented.
\end{abstract}

Keywords: Business process workarounds - Improvement opportunities - Goal misalignment analysis $\cdot$ Case study $\cdot I^{*}$

\section{Introduction}

Workarounds in business processes and information systems are a common phenomenon in practice, which has recently received considerable research attention. According to Alter [1], a workaround is "a goal-driven adaptation, improvisation, or other change to one or more aspects of an existing work system in order to overcome, bypass, or minimize the impact of obstacles, exceptions, anomalies, mishaps, established practices, management expectations, or structural constraints that are perceived as preventing that work system or its participants from achieving a desired level of efficiency, effectiveness, or other organizational or personal goals." This definition, however, is very broad, tying together quick fixes of technology mishaps, shadow IT systems, and deviations from the required course of action in business processes.

In this paper we specifically address workarounds in business processes. While generally adopting Alter's definition of workarounds, we focus on workarounds in business processes that deviate from the official process specification, but are nonetheless performed while pursuing the process goal. As an example, consider a purchasing process where an order is issued before all the required approvals are obtained. This is 
clearly a deviation from the official process, requiring an order to be issued only once all approvals have been given. Yet, the goal of the process (purchasing required goods) is pursued. Nevertheless, while technology-oriented workarounds (quick fixes, shadow IT) are often considered positively as creative and innovative solutions to existing problems, workarounds in business processes, even when promoting process goals, are typically considered negatively, as a form of intentional non-compliance, which can also harm achieving other important organizational goals as a result of focusing exclusively on one particular goal.

Business processes are designed and practiced for the purpose of standardizing, streamlining, and managing collaborative work across different units in an organizational system, thus promoting the achievement of business goals [7, 8]. Compliance with the required process is important for several reasons. First, since business processes often apply to different organizational units, standardization is an enabler of collaboration. When a process participant does not act as expected, the work of others along the process may be hampered. Second, processes frequently reflect obligations to external parties that must be met, regulations that must be complied with, and standards the organization is committed to. Last, business processes are designed to support the organization's goals, and non-compliance may impose risks and negatively impact business performance.

Our premise, which follows Alter's definition of workarounds, is that workarounds are performed for a reason, and are driven by underlying problems and limitations in the process or in the information system, the perceptions of employees, or that of their management. Analyzing and understanding the motivation behind workaround decisions may hence reveal their root causes and lead to targeted improvement solutions.

Process improvement based on workarounds has been suggested in the past (e.g., [6, 20]), but these suggestions focused on adopting the workarounds as part of the formal procedures. Evidently, when workarounds are associated with risks and other negative consequences, such adoption is not desirable. Our approach differs from previous ones in proposing a systematic goal-based analysis with the aim of revealing the problems that motivate workarounds. Improvement should be achieved by addressing these problems rather than by adopting the workarounds. Our proposed analysis is anchored in motivational theories and based on previous empirical findings. We demonstrate the analysis through an industrial case study.

The remainder of the paper is organized as follows: Sect. 2 provides background and related work about workarounds and relevant motivational theories. Section 3 describes our proposed analysis approach using $i *$ models, which is demonstrated in a case study reported in Sect. 4. Section 5 provides a concluding discussion concerning the approach and the case study.

\section{Workarounds and Goal Misalignment}

\subsection{Related Work on Workarounds}

Workarounds have been studied quite extensively in recent years, in different contexts and from different point of views. Ferneley and Sobreperez [5] suggested classifying workarounds as "harmless," "hindrance," or "essential." Determining which class is suitable, however, might differ depending on one's perspective and also reflects local 
considerations rather than organizational ones. Wilkin and Davern [20] show examples of workarounds that solve problems at an operational perspective but have harmful results at a managerial one. Recognizing this, Röder et al. [10] investigated the factors that managers weigh when deciding whether to tolerate workarounds. The findings reveal that managers consider the trade-off between possible benefits and risks resulting from the workarounds, before deciding whether to tolerate them.

Specific attention has been given to workarounds in healthcare and nursing processes, where rigid processes are sometimes impossible to follow [6]. For example, Beerepoot et al. [3] suggests criteria for accepting workarounds in healthcare processes as the formal practice or rejecting them. Still, workarounds have been observed in processes of various domains. Outmazgin and Soffer [13, 14] identified generic mechanisms by which workarounds are performed in business processes and derived patterns for detecting workarounds using process mining techniques.

In general, workarounds have been described in the literature as a goal-seeking behavior, motivated by perceived obstacles on the way to some desired goal [1]. Specifically concerning business processes, researchers (e.g., [15]) indicated that workarounds may occur when the prescribed procedures require additional effort of users and this effort is perceived as extraneous to their perceived goals. A related theme is of misfit or misalignment. Goal misalignment is mentioned as a possible source in the theory of workarounds [1]. Malaurent and Avison [9] describe workarounds in an internationally distributed organization, motivated by misalignment between headquarter intentions and the needs of local branches and subsidiary companies. Misfit as a source of workarounds, specifically in the context of ERP systems and the processes they support, was highlighted by $[17,18]$, and others.

\subsection{Organizational vs. Local-Unit Goals}

Business process management emphasizes a cross-organizational perception, guided by the aim to standardize and prescribe end-to-end procedures, as opposed to local functional "silos" [7]. Transforming employees' "siloed" perception into a crossorganizational one is considered one of the challenges associated with BPM implementation in an organization [7], while naturally the main and immediate commitment of employees is to their local unit [16]. Ideally, the goals of each local unit in the organization should be derived from global organizational goals, and realized through the corresponding business processes, all aligned with each other, as illustrated in Fig. 1.

However, very often misalignment among these elements exists or is perceived to exist for various reasons. Misalignment between organizational and local unit goals may occur when trade-off relations exist among goals, and goals set for specific local units are not highly weighed in the overall organizational perspective. For example, a specific local unit may have a goal to quickly respond and fulfill its tasks as fast as possible, while an overall consideration would also take costs into account, thus limit overtime work. Employees are typically well aware of and committed to the immediate goals of their local unit, and might not be aware of the full scope of considerations at the organizational level.

Misalignment between local goals and the process is inevitable when the goals of the local unit and of the organization are not aligned, and the process is designed to 


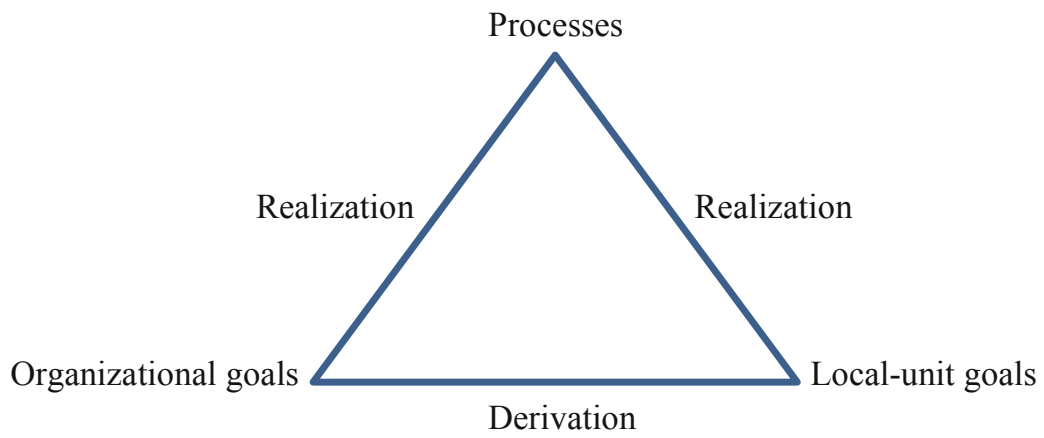

Fig. 1. An aligned goal-process triangle.

realize organizational goals. With the local goals in mind, the process is perceived as an obstacle, and this motivates a workaround. A different case would be when the process is not aligned with the local unit goals nor with organizational goals, leading to the conclusion that it is simply not well designed. We note, however, that employees act upon their perceptions, and might not be aware of the full rationale of the processes. A case where the process is aligned with the local unit goal but not with organizational goals is also possible, although less prevalent.

Our premise in this paper is that the misalignments between the elements presented in Fig. 1 drive workaround intentions. In what follows, we propose to systematically analyze goals and processes and thereby reveal misalignments using goal models.

\section{Using Goal Models for Misalignment Detection}

The three elements of the goal-process triangle can be captured using $\mathrm{i}^{*}$ models $[4,21]$, and conflicts among elements as potential drivers of workarounds can be analyzed. However, to accomplish a consistent representation, some adjustments of the modeling are needed. In $i^{*}$, the Strategic Dependency (SD) model provides a high-level representation of the actor interactions in the process, and enables understanding their dependency connections and the high-level goals that drive them. This understanding can support an examination of where the Strategic Rationale (SR) model should focus. The SR model focuses on specific actors and enables analyzing their goals and tasks, as well as positive and negative contributions among these elements. In our terms, the actors stand for local units. Since our aim is to capture conflicts between organizational goals, local unit goals, and prescribed processes, we propose the following modeling guidelines to ensure these elements are captured in the model in a consistent manner.

(1) Organizational goals and derived (local) goals: For each actor, we consider the root goal(s) as organizational goals, assigned to the actors by virtue of their role in the organization. Local-unit goals are derived from the root goal of the actor and are presented inside its boundaries. In $i^{*}$ SR models, these goals can appear as intentional goals or quality goals (ovals and clouds, respectively), as shown in Fig. 2. 
(2) Dependency goals: Each actor can have additional goals that emerge from the dependency connections with other actors. These goals support or help to achieve organizational goals primarily assigned to the other actors. In i* SR models, these goals are related to tasks or goals of the dependee actor, and are represented as derived dependency goals, as shown in Fig. 2.

(3) Tasks: All tasks presented in the $\mathrm{i}^{*}$ model are intended to realize the actor goals, both goals that are derived from dependency connections with other actors, and those that are directly derived from higher-level goals of the actor and can thus be viewed as "local".

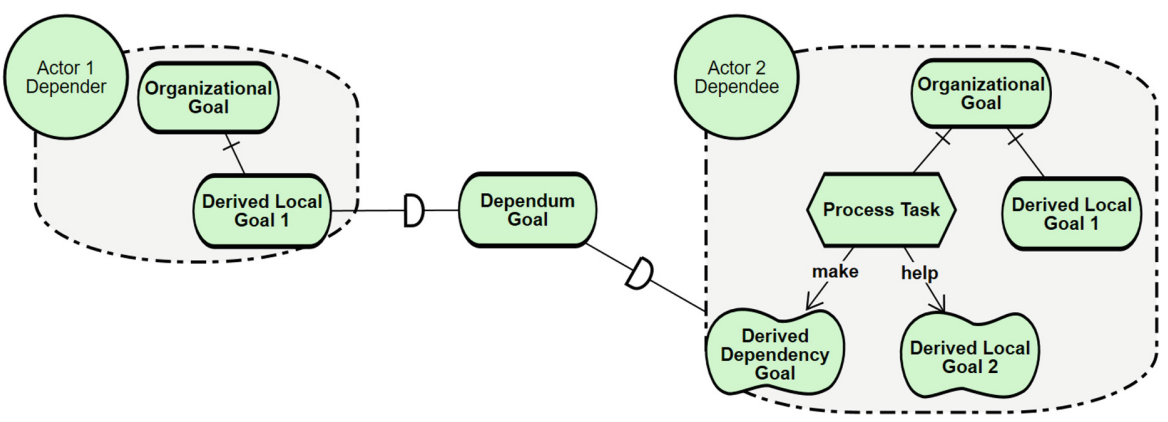

Fig. 2. Example of an $i^{*}$ model showing derivation of goals.

Since some of the derived goals and tasks of each actor stem from the actor's "own" goals (derived from organizational goals assigned to the actor), while other goals and tasks are derived from dependency relations, they are not necessarily well aligned with each other. For detecting and analyzing goal misalignment in the model, the focus should be on the negative contributions (e.g., Break or Hurt) of the goals and tasks. In fact, dependency connections with other actors create "pulling forces" on the actor in conflicting directions. The example in Fig. 3 illustrates goal misalignment detection.

As shown in the example presented in Fig. 3, the faculty head (actor 1) depends on the lecturer (actor 2), who needs to perform a task for realizing this goal. However, the lecturer has a quality goal "Flexibility with syllabus building" that is hampered by this task. The quality goal is likely derived from other goals (e.g., organizational goal - the root goal) or from dependency relations with other actors. In this example, the task creates a negative contribution (break) to the quality goal, so there is a misalignment between the dependency goal, realized by the task, and the local quality goal. 


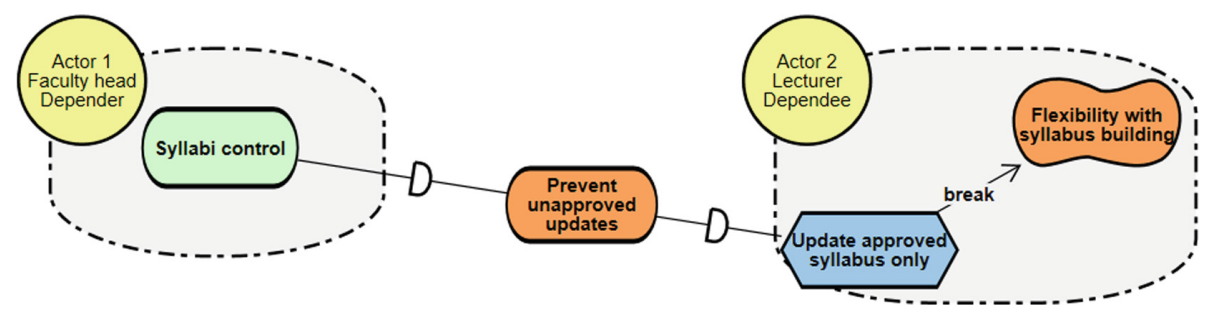

Fig. 3. Example of misalignment due to dependency relations between actors.

\section{Case Study}

\subsection{Setting and Method}

We demonstrate the proposed analysis approach through a case study, following the guidelines of interpretive case study research for understanding phenomena through the research participants' interpretation [12]. The case study was performed in a large organization operating in the domains of telecommunication, IT services, and information security. This organization employs approximately 1500 employees and is a part of a globally operating corporation that has 5300 employees. The process on which we focus is sales forecast based on price proposals, which is a cross-organizational process, involving many actors and departments, and is essential for the ongoing operations of the organization. It deals with creation, management and approval of price proposals before they can be sent to the customers. The main considerations include the profitability rate, business rules, and solution building for the customers. In addition to creation and approval of price proposals, the process deals with a variety of pre-sales activities. Ultimately, it serves for communicating opportunities and expected business deals as an operational forecast the management uses for long-term planning. The process is supported by a dedicated information system that was locally developed. It is related to other processes, such as customers sales management and purchase ordering.

We collected data through semi-structured interviews [19] with eight stakeholders of different operational and managerial roles, whose experience in the organization ranged from three to 21 years. The interviews focused on the processes as viewed by the interviewees, related goals and tasks, improvement opportunities, and workarounds that are performed (see interview guide in Table 1). We complemented the interviews by collecting documents regarding formal procedures and processes, ISO work procedures and reports, and by carefully studying the information system, its user interface, functionality, and database schema.

The interviews took 45-90 min each, and were conducted in the offices of the organization. All the interviews were audio recorded and transcribed, and in addition, phone calls and emails were exchanged after the interviews to obtain additional explanations and further validation of the interview transcripts. Following the interviews, we created a BPMN model of the process for gaining a comprehensive understanding of its flow and rules, and presented the model to the interviewees for approval. The BPMN served as an input for the detailed analysis. 
Table 1. Guiding questions for the semi-structured interviews.

\begin{tabular}{|c|c|c|}
\hline Interview questions & Goal & Used for \\
\hline \multicolumn{3}{|l|}{ Organization and process } \\
\hline $\begin{array}{l}\text { Describe your role and area of } \\
\text { responsibility in the organization }\end{array}$ & Background and introduction & Background knowledge \\
\hline $\begin{array}{l}\text { In your opinion, does the } \\
\text { organization follow clear work } \\
\text { procedures and standards like } \\
\text { ISO, SOX, JCI? Are they } \\
\text { implemented as expected? }\end{array}$ & $\begin{array}{l}\text { To understand commitments to } \\
\text { legal and external procedures, } \\
\text { policies, and regulations }\end{array}$ & Background knowledge \\
\hline $\begin{array}{l}\text { In your opinion, how are } \\
\text { organizational and procedural } \\
\text { changes managed and accepted? }\end{array}$ & $\begin{array}{l}\text { To uncover change management } \\
\text { issues, fixed paradigms and } \\
\text { resistance to changes }\end{array}$ & Background knowledge \\
\hline $\begin{array}{l}\text { What are the organization's core } \\
\text { processes? For each process } \\
\text { state: is it departmental, } \\
\text { cross-organizational or global? }\end{array}$ & $\begin{array}{l}\text { To assess the studied process } \\
\text { and examine its scope and } \\
\text { boundaries }\end{array}$ & Background knowledge \\
\hline $\begin{array}{l}\text { Describe the process from your } \\
\text { viewpoint. What would you } \\
\text { suggest in order to improve the } \\
\text { process? Do you think the IS } \\
\text { contributes to the effectiveness } \\
\text { and efficiency of the process? } \\
\text { Please elaborate }\end{array}$ & $\begin{array}{l}\text { To learn the process } \\
\text { To elicit goals sought by } \\
\text { improvement ideas } \\
\text { To uncover misalignments } \\
\text { between the as-is process and } \\
\text { the perceived goals }\end{array}$ & $\begin{array}{l}\text { - BPMN model } \\
\text { - } \mathrm{i}^{*} \text { model } \\
\text { - Conflict identification }\end{array}$ \\
\hline $\begin{array}{l}\text { What is your role in the process? } \\
\text { Do you think your areas of } \\
\text { responsibility in the process fit } \\
\text { your area of expertise? How so? }\end{array}$ & $\begin{array}{l}\text { To elicit Actor boundaries, } \\
\text { tasks, goals and dependencies } \\
\text { To elicit workarounds, possibly } \\
\text { those related to expertise }\end{array}$ & $\begin{array}{l}\text { - BPMN model } \\
\text { - } \mathrm{i}^{*} \text { model } \\
\text { - Workarounds list }\end{array}$ \\
\hline $\begin{array}{l}\text { Do you think that other process } \\
\text { participants exceed their } \\
\text { responsibility areas? How so? }\end{array}$ & $\begin{array}{l}\text { To uncover workarounds } \\
\text { performed by others }\end{array}$ & Workarounds list \\
\hline $\begin{array}{l}\text { Is there manual work in the } \\
\text { process? Where? }\end{array}$ & $\begin{array}{l}\text { To uncover difficulties in the } \\
\text { process and workarounds }\end{array}$ & Workarounds list \\
\hline
\end{tabular}

Participant's perceptions of goals and possible misalignments

\begin{tabular}{l|l|l}
\hline $\begin{array}{l}\text { From your point of view, what are } \\
\text { the organizational goals the } \\
\text { process is intended to achieve? }\end{array}$ & $\begin{array}{l}\text { To uncover perceived } \\
\text { organizational goals } \\
\text { Possibly, to elicit related } \\
\text { Were the process goals presented } \\
\text { or explained to you? }\end{array}$ & $\begin{array}{l}-\mathrm{i}^{*} \text { model } \\
- \text { Workarounds list }\end{array}$ \\
\hline
\end{tabular}


Table 1. (continued)

Participant's perceptions of goals and possible misalignments

\begin{tabular}{|c|c|c|}
\hline $\begin{array}{l}\text { What are the main goals you are } \\
\text { expected to achieve as part of } \\
\text { your role? In what ways are } \\
\text { others involved and contribute to } \\
\text { achieving these goals? }\end{array}$ & $\begin{array}{l}\text { To uncover perceived local-unit } \\
\text { goals } \\
\text { To learn the dependency } \\
\text { relations among the actors }\end{array}$ & $\begin{array}{l}\text { - } \mathrm{i}^{*} \text { model } \\
\text { - Conflict identification }\end{array}$ \\
\hline $\begin{array}{l}\text { What are the tasks you need to } \\
\text { perform although they do not } \\
\text { contribute directly to the goals } \\
\text { you are expected to accomplish? } \\
\text { Why do you need to perform } \\
\text { them? }\end{array}$ & $\begin{array}{l}\text { To elicit perceived } \\
\text { misalignments between goals } \\
\text { and tasks } \\
\text { To uncover motivation for } \\
\text { workarounds }\end{array}$ & $\begin{array}{l}-i^{*} \text { model } \\
\text { - Conflict identification }\end{array}$ \\
\hline $\begin{array}{l}\text { Are there known and defined } \\
\text { KPIs for the process? Are they } \\
\text { measured on a personal or } \\
\text { organizational level? }\end{array}$ & To elicit quality goals & $\mathrm{i}^{*}$ model \\
\hline $\begin{array}{l}\text { Are there certain situations that } \\
\text { justify performing actions other } \\
\text { than what is required in the } \\
\text { process? }\end{array}$ & $\begin{array}{l}\text { To examine and learn goal } \\
\text { misalignment situations in a } \\
\text { detailed manner } \\
\text { To elicit workarounds }\end{array}$ & $\begin{array}{l}\text { - Conflict identification } \\
\text { - Workarounds list }\end{array}$ \\
\hline $\begin{array}{l}\text { In your opinion, does the official } \\
\text { process include all the tasks } \\
\text { required to accomplish your } \\
\text { goals? If not, what do you think is } \\
\text { missing? }\end{array}$ & $\begin{array}{l}\text { To uncover perceived obstacles, } \\
\text { gaps and technological barriers } \\
\text { in the process } \\
\text { To identify process improvement } \\
\text { opportunities }\end{array}$ & $\begin{array}{l}\text { - Workarounds list } \\
\text { - Conflict identification }\end{array}$ \\
\hline $\begin{array}{l}\text { In general, are you satisfied with } \\
\text { the process? Would you suggest } \\
\text { other ways of achieving the } \\
\text { relevant goals? }\end{array}$ & $\begin{array}{l}\text { To examine improvement ideas, } \\
\text { including those already } \\
\text { performed informally (as } \\
\text { workarounds) }\end{array}$ & Workarounds list \\
\hline
\end{tabular}

Workarounds in the process

\begin{tabular}{l|l|l}
\hline $\begin{array}{l}\text { In your opinion, what is a } \\
\text { business process workaround? } \\
\begin{array}{l}\text { Do you think management would } \\
\text { define it similarly? If not, how do } \\
\text { you think they would define it? }\end{array}\end{array}$ & $\begin{array}{l}\text { To assess perceptions about } \\
\text { management view of } \\
\text { workarounds }\end{array}$ & Background knowledge \\
\hline $\begin{array}{l}\text { Are you familiar with } \\
\text { workarounds that are performed } \\
\text { in the process? If so, in which } \\
\text { situations and how often? How } \\
\text { are they identified? }\end{array}$ & $\begin{array}{l}\text { To examine and learn } \\
\text { workarounds in a detailed } \\
\text { manner, their frequencies and the } \\
\text { impact to the organization }\end{array}$ & Workarounds list \\
\hline
\end{tabular}


Table 1. (continued)

\begin{tabular}{l|l|l}
\hline \multicolumn{2}{l}{ Workarounds in the process } & \multicolumn{2}{l}{$\begin{array}{l}\text { Why, in your opinion, are these } \\
\text { workarounds performed? Do } \\
\text { these workarounds help } \\
\text { participants in accomplishing } \\
\text { their goals? Do you think that } \\
\text { these workarounds help to } \\
\text { accomplish organizational goals? }\end{array}$} & $\begin{array}{l}\text { To learn the motivation for } \\
\text { process workarounds } \\
\text { To relate the misalignment } \\
\text { situations to specific } \\
\text { workarounds }\end{array}$ & $\begin{array}{l}\text { - Workarounds list } \\
\text { - Conflict identification }\end{array}$ & \\
\hline $\begin{array}{l}\text { What do you think are the } \\
\text { consequences of these } \\
\text { workarounds? What would } \\
\text { happen if they cannot be } \\
\text { performed? }\end{array}$ & $\begin{array}{l}\text { To elicit perceived impacts of } \\
\text { workarounds }\end{array}$ & Conflict identification \\
\hline $\begin{array}{l}\text { Do you think that the process } \\
\text { workarounds are related to } \\
\text { obstacles of any kind? Do you } \\
\text { think that with a more flexible } \\
\text { process they would still be } \\
\text { performed? }\end{array}$ & $\begin{array}{l}\text { To understand the motivation for } \\
\text { performing workarounds } \\
\text { To examine process } \\
\text { improvementslopportunities }\end{array}$ & Conflict identification \\
$\begin{array}{l}\text { In your opinion, are workarounds } \\
\text { performed regularly? Do they } \\
\text { require skills or deep familiarity } \\
\text { with the process? }\end{array}$ & $\begin{array}{l}\text { To clarify the motivation and the } \\
\text { effort involved in workarounds }\end{array}$ & Workarounds list \\
\hline
\end{tabular}

Text analysis and interpretation of the transcribed interviews were performed to identify the process goals as perceived by the interviewees, gradually constructing goal and dependency diagrams. In particular, conflicts and misalignments were sought between the identified goals and between the goals and the process, as depicted in the validated BPMN. This was done following the guidelines outlined in Sect. 3. In parallel, we listed the workarounds reported in the interviews. Following our assumption of correlation between workarounds and misalignments, we used the list of workarounds as triangulation for the identified misalignments, and iterated to reveal additional misalignments that could be related to the reported workarounds. Last, we proposed solution directions for the identified misalignments and presented them for evaluation to the director of procedures and methods, pre-sale department manager, and sales department manager.

\subsection{Goal Misalignment Detection}

According to the approach presented in Sect. 3, we first created the SD model of the sales forecast process for understanding the dependencies between the actors and the main organizational goal pursued by each of them, and then we zoomed into the SR model to examine and focus on the misalignment detection. 
As shown in the SD model in Fig. 4, the customer manager is the main actor of the sales forecast process, and hence a detailed SR model was created for this actor. The main goal of this actor is to promote sales according to the sales targets. This is done while creating the price proposal, gradually building the solution offering with the related part numbers and specification, service agreement, and a full "proposal kit." Every detail needs to be approved through an approval round by several role holders, until a customer commitment to purchase the content of the price proposal is received.

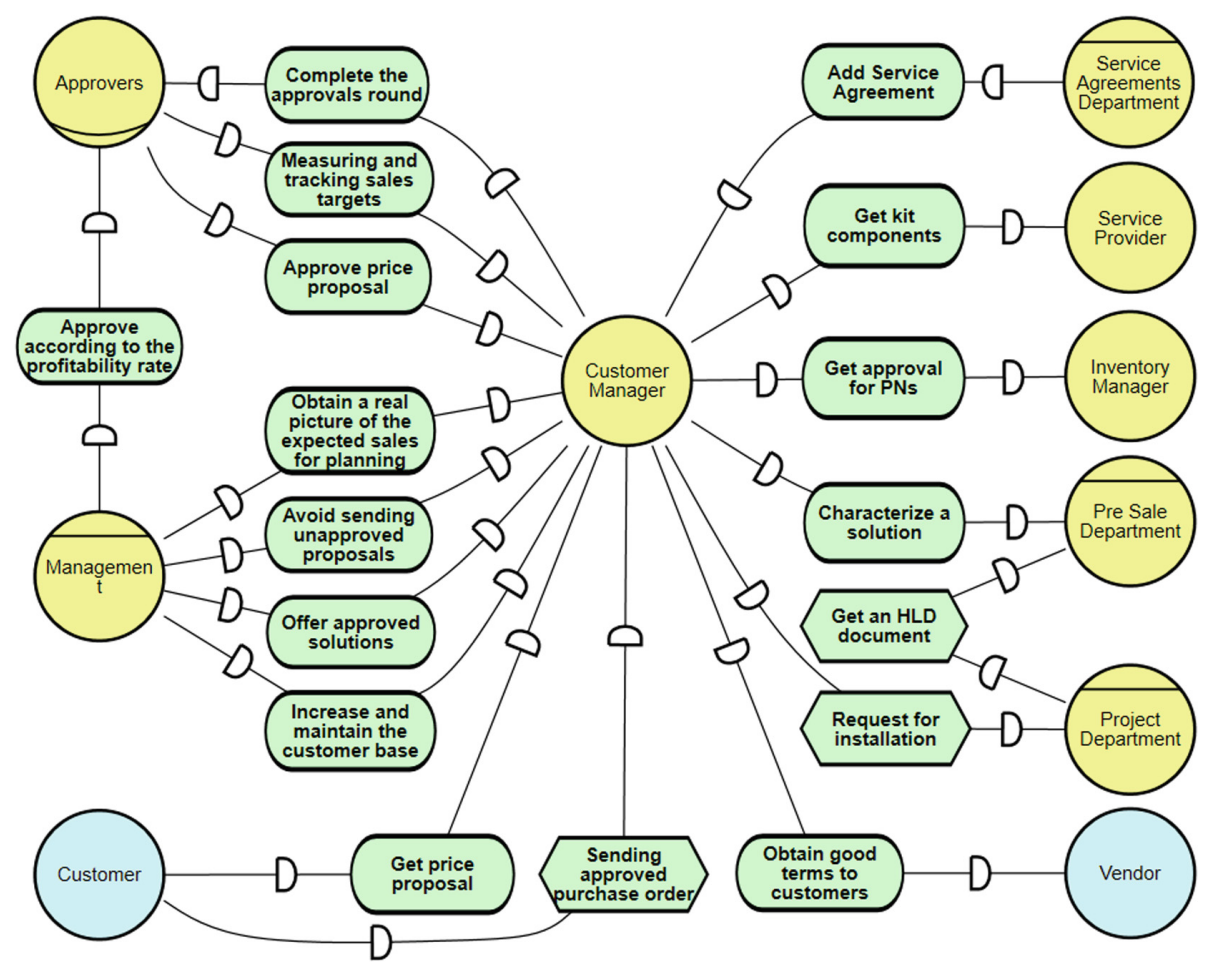

Fig. 4. SD model of the sales forecast process.

To execute this process, the customer manager has two directions of dependencies with other actors. In one direction, the customer manager depends on other actors (e.g., the approvers, the service provider). The second direction is where other actors depend on the customer manager (e.g., management, service agreements department).

Due to space limitations, we cannot show and discuss the details of the entire SR model. Rather, we focus here on two relatively simple examples to illustrate the analysis approach. The first example illustrates a goal misalignment related to local goals derived from the dependencies with external actors, and the second example illustrates a goal misalignment related to local goals derived from their root goal. In both examples the misalignment is between those goals and the goals of the external actor through the dependencies, as follows: 


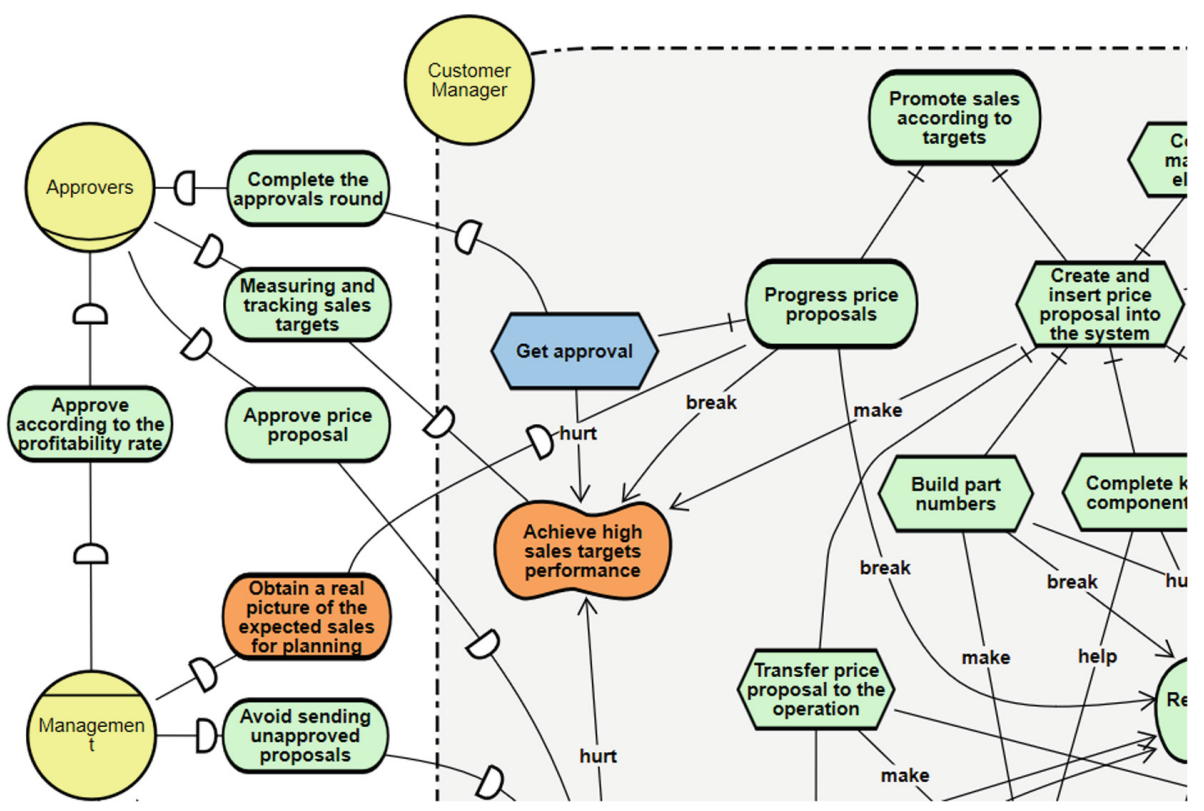

Fig. 5. Example A.

(1) Goal misalignment was detected between the "Achieve high sales targets performance" and "Obtain a real picture of the expected sales for planning" goals. In Fig. 5, the dependency of the management actor for the goal "Obtain a real picture of the expected sales for planning" relates to the goal "Progress price proposals" of the customer manager, since when price proposals are entered and progressed in the IS, they are visible to management and serve as an indication of expected future sales. However, the model shows a negative contribution (break) to the goal "Achieve high sales target performance". The explanation is that sales target performance is measured based on the rate of price proposals, which are realized as sales orders. To achieve high sales target performance, the customer manager needs to enter price proposals only towards the closing of a deal, when they are almost certain to lead to an actual sale. In addition, the regular approval rounds associated with progressing price proposals may delay the process, and reduce sales performance, as seen by the hurt relation between "Get approval" and "Achieve high sales target performance".

(2) Goal misalignment was detected between the goal "Avoid sending unapproved proposals" and the goals "Respond quickly and flexibly" and "Satisfy the customer" goals. In Fig. 6, the dependency of the management actor for the goal "Avoid sending unapproved price proposals" relates to the task "Send the approved price proposal to the customer" of the customer manager. This leads to a negative contribution to two goals: it hurts the "Satisfy the customer" goal and breaks the "Respond quickly and flexibly" goal. This is because of the requirement of management to only send to the customers price proposals that completed the approval round, both for new 


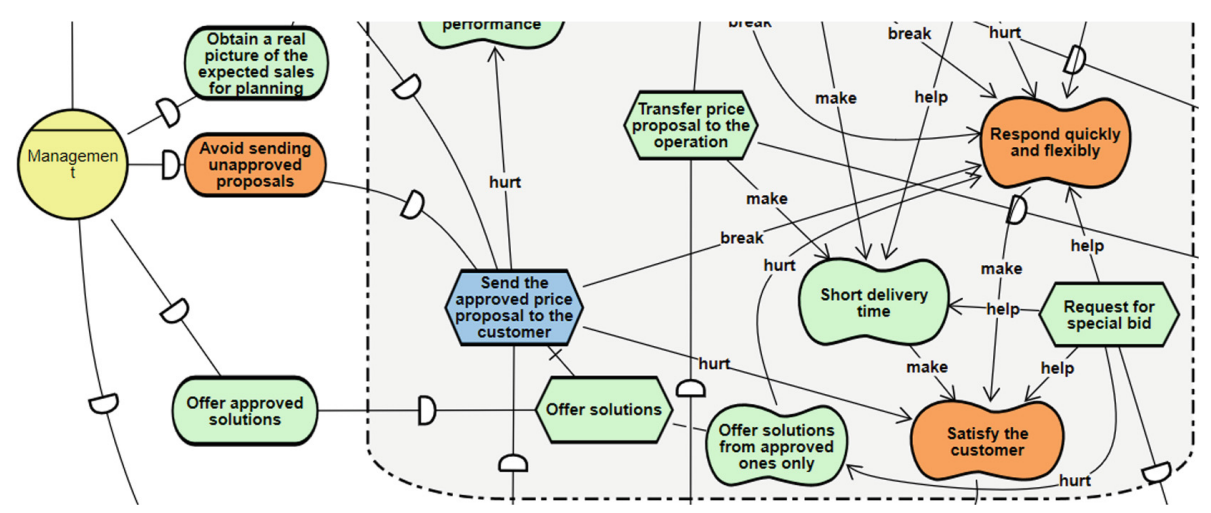

Fig. 6. Example B.

price proposals and for each change in the proposal introduced after its approval. As a result, the customer manager cannot respond quickly and the satisfaction of the customers can be reduced.

\subsection{Workarounds}

As described in Sect. 4.1, we collected workarounds independent of the misalignment analysis, and looked for connections between workarounds and misalignments. Eventually we could associate each of the workarounds with one or more of the identified misalignments, and vice versa. We demonstrate this for the misalignment examples presented above:

Example A - Workaround Description: The customer manager creates a new price proposal in the IS only after closing the deal with the customer. Specifically, all negotiations with the customers are done unofficially without any record in the IS. Only after receiving a signed purchase order from the customer does the customer manager start the process of creating a price proposal and getting all the required approvals. Evidently, the customer manager works around the process and gets a post-factum approval for the price proposal.

Underlying Misalignment: Between the goals to achieve high sales target performance measures and to manage and progress the price proposals, which, in turn, supports the management goal to have a forecast of potential sales ahead of time in order to plan for it. The sales target performance is based on the price proposals which actually materialize into a sales order. Hence, the customer manager is not motivated to report unclosed deals.

Result: Price proposals that are still in process, before closure, do not exist in the IS and so they cannot be considered by management for planning, i.e., management actor's goal to obtain a real picture of the expected sales for planning purposes is hampered. 
Example B - Workaround Description: The customer manager prepares and sends price proposals to customers manually, before they exist in the IS. The customer manager uses Word documents or Excel spreadsheets and sends them to the customers directly in regular email, and so these actions are not documented in the IS.

Underlying Misalignment: Between the goals of the customer manager to respond quickly and flexibly and to satisfy the customer and the task (official process) of sending price proposals only after they are approved. If the customer manager waits for an approval for each new price proposal as well as for each change in the proposal introduced after its approval, the quick and flexible response goals would not be achieved, and customer's satisfaction might be reduced.

Result: Harm can be caused for the organization by sending unapproved price proposals that might create commitment to unprofitable or risky deals.

\subsection{Improvement Opportunities}

Using the goal models and identifying their correspondence to reported workarounds, we were able to reveal various misalignments and understand how they drive workaround situations. This understanding can be leveraged and yield improvement opportunities for the business process. Based on the examples above, the following improvements were suggested to the organization:

(1) Changing the measures used for assessment of the sales performance - as the customer managers are currently evaluated for sales target performance in a way that motivates them to avoid entering price proposals to the IS until closure of all the details of the deal. Therefore, the suggestion is to change the measures of the sales target performance to ones that would eliminate the conflict between high sales performance (calculated based on the percentage of materialized price proposals) and managing the price proposals in the IS. For example, changing the measure to reflect the number of sales opportunities, sales activities or potential sales income can motivate the customer managers to enter price proposals as soon as possible and manage them through the IS, resulting in alignment between the sales performance goal and that of documenting and progressing price proposals in the IS. In addition, the measure can also consider customers' billing rate, to motivate the customer managers to supervise price proposals all the way down to ordering and payment.

(2) Reducing the strictness of the procedure of approvals and approval rounds. We propose to do this in two ways. First, by introducing threshold conditions for the amount and the profitability rate of the price proposals that require approval. This would increase the degree of freedom for the customer managers and enable a quick processing of small price proposals. Second, by introducing several different approval trails that can be selected according to price proposal amounts and the profitability rate, and considering whether this is a new price proposal or a change in an existing one. Currently, each price proposal for any amount requires the same approval round and the same approvals hierarchy. Our suggestion is to offer a shorter and 
quicker route for proposals or changes that are of relatively low risk (new proposals of small amounts or small changes of approved proposals). These suggestions can significantly increase the flexibility of the customer managers in the negotiation with the customers and shorten response times, thus increasing the customer satisfaction level. The task would change to sending prices proposals according to the approval policy, and this would still be aligned with the management goal of avoiding sending unapproved proposals while introducing minimal delay to this process.

The suggested improvement ideas and the relevant goal misalignment situations were presented in the case study organization to the director of procedures and methods, the pre-sale department manager, and the sales department manager. The suggestions were discussed in the organization and approved as an improvement plan. Currently these improvements are being implemented in the organization.

\section{Concluding Discussion}

In this paper, we have shown how workarounds in business processes can be analyzed systematically using goal models, and how this analysis can reveal the underlying problems that motivate workarounds. Thus, this analysis can lead to targeted and ongoing process improvement.

Earlier suggestions have been made to utilize workaround information for process improvement (e.g., [6, 20]). These, however, mostly suggested to adopt the workaround as a formal procedure when appropriate. In contrast, we aim to reveal the problems and, specifically, the perceived misalignments that drive the workaround intention, and to solve them. Addressing the problems directly may yield other solutions, which may be more beneficial or less risky than the workarounds that are taken.

Our analysis differs from previously suggested analysis approaches, which typically focused on the workarounds themselves. Examples include [2] and [3], where workarounds are studied and analyzed for determining whether they are acceptable as an official process, and [10], where responses of managers to workarounds are considered. In [11] workarounds are represented as designated parts in process models so they can be visualized and recognized, but not in relation to their sources.

In contrast, we focus on the conflicts and misalignments underlying existing workarounds, using the well-established $i *$ model. With this we gain another advantage - the information needed for constructing a goal model is easier to obtain than information concerning workarounds. Employees are likely to be much more cooperative regarding their goals and actions than regarding workarounds they perform.

The reported case study demonstrates how misalignment of goals and processes can be recognized in an $i^{*}$ model and associated with workarounds that are performed in the process. The guidelines we suggested for the creation of the $i^{*}$ model are intended to enable a consistent representation of how local goals and tasks are derived from organizational goals and from dependencies among actors for realizing these goals. The interview guide that was used is generic and can be used in similar projects. We further demonstrate how improvement suggestions can be made when specifically addressing 
the revealed misalignments. The specific suggestions we made have been evaluated in the case study organization and found adequate to the extent that they are currently being implemented. This indicates the potential of our approach, whose main idea is to leverage workarounds for process improvement by addressing their sources rather than the workarounds themselves, which are rather a symptom than a solution.

Toward using this analysis method in industry, it is important to consider and address the following challenges: (1) properly build and use $i^{*}$ models - the analysis should be performed by professional analysts, who are familiar with $i^{*}$ modeling; (2) implement $i^{*}$ according to the proposed analysis guidance, in the context of capturing global and local goals - analysts should understand and follow the guidance, which could possibly require some training; and, (3) rely on openness of employees in interviews - different questions posed around central topics allow for some triangulation of the elicited information, in order to mitigate risks of social-serving bias and other biases potentially affecting employees' responses.

Several limitations need to be acknowledged. The approach proposed in this paper was thus far implemented in a single case study. Additional implementations in different organizations would provide a more generalizable view of the benefits of this approach. The approach uses interviews as a central means for eliciting data, which is subject to report and self-serving biases. This limitation is mitigated, to some extent, by triangulation with data elicited from complementary sources (see Sect. 4.1).

Future research can focus further on the complementary data sources and search for ways to extract some of the information in automatic ways, for example, based on log events analysis, reducing human effort required for the workaround analysis process.

Acknowledgement. The research is supported by the Israel Science Foundation under grant agreement 669/17.

\section{References}

1. Alter, S.: Theory of workarounds. Commun. Assoc. Inf. Syst. 34(1), 1041-1066 (2014)

2. Alter, S.: A workaround design system for anticipating, designing, and/or preventing workarounds. In: Gaaloul, K., Schmidt, R., Nurcan, S., Guerreiro, S., Ma, Q. (eds.) CAISE 2015. LNBIP, vol. 214, pp. 489-498. Springer, Cham (2015). https://doi.org/10.1007/978-3319-19237-6_31

3. Beerepoot, I., Ouali, A., van de Weerd, I., Reijers, H.A.: Working around health information systems: to accept or not to accept? In: Proceedings of the $27^{\text {th }}$ European Conference on Information Systems (ECIS 2019) (2019)

4. Dalpiaz, F., Franch, X., Horkoff, J.: istar 2.0 language guide (2016). arXiv preprint arXiv: 1605.07767

5. Ferneley, E.H., Sobreperez, P.: Resist, comply or workaround? an examination of different facets of user engagement with information systems. Eur. J. Inf. Syst. 15(4), 345-356 (2006)

6. Friedman, A., et al.: A typology of electronic health record workarounds in small-to-medium size primary care practices. J. Am. Med. Inf. Assoc. 21, 78-83 (2014)

7. Hammer, M.: What is business process management? In: vom Brocke, J., Rosemann, M. (eds.) Handbook on Business Process Management 1. IHIS, pp. 3-16. Springer, Heidelberg (2015). https://doi.org/10.1007/978-3-642-45100-3_1 
8. Harmon, P.: Business Process Change: A Guide for Business Managers and BPM and Six Sigma Professionals. Morgan Kaufmann, Burlington (2010)

9. Malaurent, J., Avison, D.: Reconciling global and local needs: a canonical action research project to deal with workarounds. Inf. Syst. J. 26(3), 227-257 (2016)

10. Röder, N., Wiesche, M., Schermann, M., Krcmar, H.: Why managers tolerate workaroundsthe role of information systems (2014)

11. Röder, N., Wiesche, M., Schermann, M., Krcmar, H.: Workaround aware business process modeling. In: Wirtschaftsinformatik, pp. 482-496 (2015)

12. Runeson, P., Höst, M.: Guidelines for conducting and reporting case study research in software engineering. Empirical Softw. Eng. 14(2), 131 (2009). https://doi.org/10.1007/s10664-0089102-8

13. Outmazgin, N., Soffer, P.: Business process workarounds: what can and cannot be detected by process mining. In: Nurcan, S., et al. (eds.) BPMDS/EMMSAD -2013. LNBIP, vol. 147, pp. 48-62. Springer, Heidelberg (2013). https://doi.org/10.1007/978-3-642-38484-4_5

14. Outmazgin, N., Soffer, P.: A process mining-based analysis of business process workarounds. Softw. Syst. Model. 15(2), 309 (2016). https://doi.org/10.1007/s10270-014-0420-6

15. Poelmans, S.: Workarounds and distributed viscosity in a workflow system: a case study. ACM SIGGROUP Bull. 20(3), 11-12 (1999)

16. Sobreperez, P.: Technological frame incongruence, diffusion, and noncompliance. In: León, G., Bernardos, A.M., Casar, J.R., Kautz, K., De Gross, J.I. (eds.) TDIT 2008. ITIFIP, vol. 287, pp. 179-196. Springer, Boston, MA (2008). https://doi.org/10.1007/978-0-387-875033_10

17. Strong, D.M., Volkoff, O.: Understanding organization-enterprise system fit: a path to theorizing the information technology artifact. MIS Q. 34(4), 731-756 (2010)

18. van Beijsterveld, J.A., Van Groenendaal, J.H.: Solving misfits in ERP implementations by SMEs. Inf. Syst. J. 26(4), 369-393 (2016)

19. Walsham, G.: Doing interpretive research. Eur. J. Inf. Syst. 15(3), 320-330 (2006)

20. Wilkin, C.L., Davern, M.: Acceptance of post-adoption unanticipated IS usage: towards a taxonomy. Data Base Adv. Inf. Syst. 43(3), 9-25 (2012)

21. Yu, E.: Modelling strategic relationships for process reengineering. Soc. Model. Requirements Eng. 11, 2011 (2011) 